\title{
The Effectiveness of a Proposed Enrichment Program in Developing Geographical Concepts and Cosmic Awareness among High School Students in Saudi Arabia
}

\author{
Fawziah M. Aldosary ${ }^{*}$
}

\begin{abstract}
The current study is an attempt to investigate the effectiveness of an enrichment program to develop geographical and cosmic concepts and knowledge among second year high school students in the Kingdom of Saudi Arabia (KSA). The population consisted of second year female high school students in the Humanities stream, for the academic year $2016 / 2017$. The sample of the study consisted of 50 randomly selected students who were divided into two groups, experimental (25) and control (25). The quasi-experimental method was adopted in this study. Results show that the proposed enrichment program had a positive effect on the female students' achievement of geographical and cosmic concepts and the development of cosmic awareness. It is recommended that training courses should be conducted for pre and in-service teachers in order to change the Geography curriculum from an achievement curriculum into an enrichment one, and to enrich it with activities that develop geographical and cosmic concepts and cosmic awareness.
\end{abstract}

Key Words: Enrichment program, Geographical and cosmic concepts, Cosmic awareness

\section{Introduction}

Scientific concepts are the core of the educational process, on which learning the different pieces of knowledge is based. They are one of the key components of the cognitive structure and comprise the basic building blocks of science. In addition, they represent the real tool of science on which sound scientific learning is based.

Scientific concepts have developed from being one of the many aspects of learning to become the main core on which the programs of educational institutions are focused. This may be observed in the projects of educational development. Hence, the attention of educators in the different stages is grasped to teaching such concepts that form a necessary hierarchical basis of the cognitive behavior. It requires a long period to gradually transfer concepts from ambiguity to clarity. Additionally, the largest burden of developing such concepts lies on school (Elobedy, 2006).

Learning scientific concepts lies in simplifying the real world to increase communication and understanding. Concepts represent an organized structure which helps

\footnotetext{
College of Education, Princess Nourah bint Abdulrahman University, Riyadh, Saudi Arabia
} 
organize learner's experiences in an easy to recall way. In doing so, they categorize things and situations and help in the prediction and planning of activities. Additionally, concepts increase learners' ability to use science functions of interpretation, control and predication. Furthermore, they allow learners to organize and connect events to acquire the necessary information to help them understand and interpret new experiences (Zaetoun, 2004).

Because of their importance, pioneers of education agreed on the necessity of acquiring these concepts. They were considered one of the main educational objectives to be accomplished, and appropriate teaching methods were expected to help learners acquire and memorize geography concepts (Ellaqany, et al. 1990).

As a science, geography is related to concepts consisting of a correlated set of facts, generalizations, theories, skills and attitudes, taking a hierarchy that begins with a broad base of knowledge and facts that are correlated and categorized according to common standards to form concepts. These concepts are then correlate to form generalizations that form theories. Hence, cognitive aspects of skills and attitudes are created from the emotional ones. It is guaranteed that this structure is not stable because of development and continuing change of sciences and knowledge as well as the results of scientific research and technological development (Ellaqany, 1990).

Thus, for the subject of geography, geographical concepts are the most important level of the cognitive structure, on which the other levels of principles, generalizations and theories are based. They are also used to organize the cognitive skills of the learner that could be organized to form valuable learning. This cannot be accomplished by simply using various teaching strategies and methods. Many educational studies reported the necessity of using various teaching strategies and methods to develop geographical concepts. For example, Ahmad (2012) aimed to identify the effectiveness of a thinking map-based teaching strategy to develop geographical concepts and geographical thinking skills among first-year preparatory school students. This approach was found to be effective in developing concepts and igniting students' interest in developing geographical concepts. Eladwan (2011) studied the effectiveness of using learning cycle strategy in acquiring geographical concepts among basic 10th-year students. The results indicated the importance of paying attention to acquiring and teaching geographical concepts. In a related study, Abdelmowla (2010) reported the effectiveness of using mixed methods of teaching social studies in developing geographical concepts among first-year vocational preparatory students.

The development of cosmic concepts among the learners is one of the most significant objectives of teaching geography because of the role they play in making them aware of the greatness of the Creator. This is the foundation of knowledge whereby learners can grasp cosmic problems and realize their responsibility towards this universe.

Many researchers have reported the importance of helping learners to understand all stages of the issues related to space. For example, Elattar (2002) aimed to identify concepts about the earth and space, proposing a treatment program. He stressed the necessity of paying attention to cosmic concepts. Mahmoud (2002) studied the impact of a proposed unit, entitled (earth and atmosphere), on learners' achievement in and attitude towards science. She observed the importance of acquiring cosmic concepts because of their impact on achievement. In a study of the concepts and issues related to space by the students of Faculties of Education, specialization of Science, Jad (2003) found that the sample were unable to master the concepts and issues related to space despite their scientific importance. Brunsell \& Marcks (2007) aimed to identify learners' understanding 
of space science scope, offering educational activities that proved to be effective in acquiring sound science concepts. Ashmann (2012) aimed to change the frames of reference related to lunar phases among learners by applying a set of activities, resulting in a change of learners' frames of reference.

This conceptual aspect, represented in a deep understanding of this knowledge and information, is based on the emotional aspect, comprising values, and attitudes. The level of awareness is the first step of forming the spiritual aspect. Although it is ranked the lowest in the emotional categorization, developing this aspect is a key basis of treating any problem, not only in understanding the problem or its causes but also to form a belief among individuals that they are able and ready to control and limit their negative behaviors. This shows the importance of learners' awareness of the problem and trying to eliminate or control it.

The relationship between awareness of problems and solving them is a reciprocal one because it is not represented in the lack of adequate awareness of the problem. This leads to their aggravation and inability to solve them. Decreased awareness results into dangerous problems. That is, human problems are increased due to the lack of awareness of the wrong behavior towards environment and community (Tammam, 2012)

Therefore, developing learners' awareness of geographical problems, in general, and cosmic ones, in particular, is essential as it is not related to certain communities or environments, but to the whole world. It includes problems such as ozone hole widening, cosmic pollution, and global warming. Development of awareness is an educational necessity and requirement. The development of learner's cosmic awareness contributes to deepening the feeling of belonging to this world and enables the learner live in harmony with the surrounding environment, apart from acquiring higher order thinking skills (critical and creative thinking). Developing learners' awareness of cosmic problems by grasping and understanding geographical concepts related to cosmic problems is therefore one of the most significant objectives of geography course.

It could be concluded that education has to prepare a man belongs to the world; a man of the age of globalization and exciting discoveries; and a man with special features who seeks progress and coping up with the age. Such progress is mainly based on defining the man's type and awareness of the world's conditions, problems and challenges because the level of awareness still largely reflects countries' quota of development, underdevelopment and the size of some cosmic problems.

Such conceptual identification and cosmic awareness cannot be accomplished without offering enrichment educational activities. Anderson et al. (1994) reported that such activities are a key pillar of teaching and learning science. In addition, they are a modern attitude of simplifying science, in which scientific information is attractively presented without violating the scientific credibility of knowledge. Furthermore, they make teaching agree with the surrounding environment and supports learners in their development as independent thinkers who are confident in their abilities.

Accordingly, providing geographical and cosmic concepts requires enrichment programs that display concepts in a new scientific way that forms cosmic awareness of the learner. Activities that have been successfully used to develop cosmic awareness: gradation of abstraction, simplification or entering former requirements to make it clearer, using information in life, considering learners' individual differences, bridging the gap of course organization and sequence of experiences, creating concepts; the more examples are, to a 
certain limit, the easier creating concepts becomes, and developing the concept; the more, wider and deeper examples are, the easier concept development becomes. (Alostaz and Matar, 2001).

Enrichment is not only accomplished through curricula planning, creation and development only, but also through the necessary process of periodic/regular updating and enriching from time to time (Qanou, 2013). Many researchers have studies enrichment programs in teaching about space. For example, Ahmad (1999) used some educational activities in teaching the space unit in order to develop creative thinking and imagination. His findings showed the importance of enrichment programs because they are significant elements in the educational process.

Enrichment programs can be subdivided into horizontal and vertical. Horizontal Enrichment means adding new chapters and experiences to the original chapters of a number of courses. Vertical Enrichment means deepening the content of certain units in a specific course or curriculum to provide learners with rich experiences in a certain topic only. Both types of enrichment help to substantially increase the knowledge of the material related to the curriculum (Soliman, 2010; Muhammad, 2013). In the current study, the author used vertical enrichment that includes adding to female learners' experiences related to geographical concepts and cosmic awareness through teaching activities that agree with the content to be studied. This was suitable for the educational system applied in schools and does not require complex school organizations.

From the foregoing literature, it can be concluded that using an enrichment program could help in developing the achievement of geographical concepts, in general and cosmic ones in particular. While some studies worked on using enrichment activities to develop cosmic concepts, they did not offer any enrichment program to develop geographical and cosmic concepts and cosmic awareness, to the author's knowledge. Therefore, the present study focuses on developing geographical and cosmic concepts and cosmic awareness of female learners by using an enrichment program.

The study attempted to answer the following question: What is the effectiveness of a proposed enrichment program in developing geographical concepts and cosmic awareness among $2^{\text {nd }}$ grade female high school students from the Humanities stream? This presupposes the following sub-questions: What is the effectiveness of a proposed enrichment program in developing geographical and cosmic concepts among the $2^{\text {nd }}$ grade female high school students in Humanities stream? What is the effectiveness of a proposed enrichment program in developing cosmic awareness among the $2^{\text {nd }}$ grade female high school students from the Humanities stream?

It was hypothesized that:

1- There are statistically significant differences at the level of $(\alpha \geq 0.05)$ between the means of experimental and control groups' scores for the post-test of geographical and cosmic concepts.

2- There are statistically significant differences at the level of $(\alpha \geq 0.05)$ between the means of the experimental and control groups' scores for the pre-test of cosmic awareness scale.

3- There are statistically significant differences at the level of $(\alpha \geq 0.05)$ between the means of the experimental and control groups' scores for the post-test of cosmic awareness scale. 
The significance of the current study has been defined in a number of theoretical and field factors, the most significant aspects are: The low level of cosmic culture knowledge among high school students. Elbarghothy et al. (2002) reported that high school students have a low level of astronomical knowledge (p. 15). Jad (2003) concluded that learners are unable to understand concepts and issues related to space. It is a pioneering study; rather it is the first to the author's knowledge that study cosmic concepts and cosmic awareness among the female learners. It is also a reason for conducting the current study.

The significance of the current study lies in the following points: It is a response to the reflection of Allah's creation of the universe; understanding the relation that connects the universe's parts and components; and defining its relation to the earth and that of the earth to plants, stars and outer space. It supports the efforts exerted in the field of educational researches related to space issues. The author aims that this study adds to the experimental research and consolidates literature. It provides a proposed design of an enrichment program in geography to develop geographical and cosmic concepts and cosmic awareness. It is the first, to the author's knowledge, in the field of using an enrichment program to develop geographical and cosmic concepts and measure cosmic awareness. It provides the scale of cosmic awareness to some cosmic issues.

\section{Population \& Sampling}

The population of the study comprised $2^{\text {nd }}$ grade female high school students in the Humanities stream at Saudi public schools. These students studied geography during the second semester of the academic year 2015/2016. The entire grade population of 50 female students was randomly assigned to two groups: experimental group of 25 students and control group of 25 students.

\section{Methodology}

According to the nature of the study, the author used quasi-experimental design that means designing non-equivalent groups and depends on using two groups; experimental and control (Awda and Malkawy, 1992).

To answer the study's questions and verify its hypotheses, the author adopted the following procedures:

\section{Unit Selection}

"Universe" unit of the geography textbook $2^{\text {nd }}$ grade in the academic year 2015/2016 was selected because: It includes many subjects that represent an important aspect of the cognitive structure of space, e.g. galaxy, planets, and the sun. It covers a large set of concepts related to the life of the female students that require explanation and interpretation, e.g. global warming and cosmic pollution. It covers many abstract concepts, e.g. nebula, stars, asteroids, falling stars, meteors, and orbit. It is traditionally taught in public schools, as the author observed, in the field visit to some schools. 


\section{Enrichment program}

A. Brief description: The enrichment program aims to prepare programs of enrichment activities that include concepts, skills and generalizations embedded in "universe" unit. It also aims to develop the achievement of geographical and cosmic concepts and cosmic awareness among high school 2nd grade female students, Humanities stream, using the computer.

B. Procedural objectives: The performance expected of high school 2nd grade female students.

C. Contents of the program: To define its contents, the author analyzed the content of geography course to be studied by high school 2nd grade female students, Humanities stream to generate geographical and cosmic concepts embedded in "universe" unit using content analysis. She made a list of geographical and cosmic concepts of (30) concepts. After reviewing literature, the unit was designed in the form of scientific material, various activities (scientific and consolidating) and exercises, considering embedding all the enrichment program's concepts. It was taught using the computer. Hence, the first question has been answered: What are the geographical and cosmic concepts impeded in "universe" unit of geography course among the high school $2^{\text {nd }}$ grade female students, Humanities stream?

D. Teaching the enrichment program to the control group: The author reordered the content of "universe" unit and its contents of exercises and activities by teaching the unit via the computer. She concentrated on sense motives (visual and auditory) to configure the educational environment to be more exciting.

\section{Instruments:}

The instruments for data collection included in geographical and cosmic concepts test and the cosmic awareness scale both developed by the researcher.

\section{a. Geographical and Cosmic Concepts Test:}

It is an achievement test that aims to measure geographical and cosmic concepts based on the following levels:

I. Recall and understanding: Recall is the ability of the learner to recall knowledge and facts related to "universe" unit. Understanding is the learner's ability to grasp the relations of facts, knowledge and generalizations related to the unit.

II. Application: it means the learner's ability to use geographical concepts and relations in solving problems or current issues.

III. Solving problems and issues, including (analysis, synthesis and evaluation). Analysis is the learner's ability to decompose the material into smaller components, following their relations and their organization methods. Synthesis is the learner's ability to gather items and parts in a comprehensive whole, if it was formerly unclear. Evaluation is the learner's ability to judge the validity of solutions and information.

Therefore, the author followed these procedures: Designing vocabularies of geographical and cosmic concepts test:

- Formulating the test's vocabularies to be an objective test including questions of correct and wrong, multiple choice and comparison of (30) items.

- Formulating test instructions clearly to guide the female students in their answers, e.g. objectives, time and how to answer. 
- Defining relative weights of the questions embedded in geographical and cosmic concepts test: the table of specifications has been set, including the distribution of test items on the cognitive aspects and defining their relative weight in a balanced manner with the topics of the content.

- Reviewing the test: After preparing the test in its first draft, it was reported to a group of evaluators to estimate its face validity by conducting the pilot experiment. It was applied to (6) female students of the population to measure correlation coefficient of the scores of each question and those of the whole test, rating (0.90). To test its reliability, it was re-applied after two weeks. After applying Cronbach's alpha, it rated (0.84), indicating that it is valid and appropriate. Abuhashem (2004) reported that if the reliability coefficient rated $(80 \%)$, it is high.

- In addition, the coefficients of easiness, difficulty and diversity of the test vocabularies has been defined, rating (0.20- 0.85), (0.21-0.77) and (0.44- 0.83), respectively. Therefore, the questions are educationally acceptable.

- The final form of the test: After estimating its validity and reliability, the test is valid for application.

\section{b. Cosmic Awareness Scale:}

It aims to measure the construct of cosmic awareness among students. The author followed these steps to design the scale:

- Formulating the scale's vocabularies: The author conducted a theoretical study of the female students' awareness of cosmic phenomena and outer space to define the aspects of cosmic awareness. The scale of situational awareness comprised many items that were sub-categorized into three dimensions: A. Causes of cosmic problems B. Results C. Solutions. Cosmic awareness scale consisted of (30) items under three considerations: desire to know outer space, readiness to conduct activities related to the universe and enjoy studying. Each situation is measured using a three-item scale to define the individuals' awareness of the former dimensions. They were formulated in an argumentative way. In addition, the author provided these responses (agree- uncertain- disagree).

- Clearly formulating the instructions to guide the female students, covering: components, aim, time, how to respond to each phrase, example of a similar situation and an instruction that there is not wrong or correct answer. The female student has to choose based on personal opinion. In distributing the behavioral situations, a kind of balance between positive and negative items was considered so that they are arbitrarily distributed.

- Grading matrix: If the response is positive, they are rated as follows: agree, uncertain, disagree $(3,2,1)$ scores, respectively. If it is negative, they are rated as follows: disagree, uncertain, agree $(3,2,1)$, respectively. Hence, the maximum score is 90 and the minimum one is 30 .

- Reviewing the scale: After reviewing and evaluating the test in its first draft, it was reported to a group of reviewers and evaluators to estimate its face and structural validity by conducting the pilot experiment. It was applied to (10) female students of the population to measure correlation coefficient of the scores of each item and those of the whole scale, rating (0.83). To measure reliability, the KuderRichardson Formula was used, rating (0.683) which is a high percentage. 


\section{Results}

Geographical and cosmic concepts test was pre-tested on the two groups of the study. Table (1) illustrates the results of Man Whitney test of the differences between the research groups in the pre-test of geographical and cosmic concepts test

Table (1) Results of Man Whitney test of the differences between the control and experimental groups in the pre-test of geographical and cosmic concepts test.

\begin{tabular}{lccccc}
\hline \multicolumn{1}{c}{ Group } & Size & $\begin{array}{c}\text { Total of } \\
\text { ranks }\end{array}$ & $\begin{array}{c}\text { Means } \\
\text { of ranks }\end{array}$ & $\begin{array}{c}\text { Man } \\
\text { Whitney } \\
\text { Test }\end{array}$ & Significance \\
\hline Experimental & 6 & 39 & 6.5 & & 1 \\
Control & 6 & 39 & 6.5 & & \\
& & & & & \\
\hline
\end{tabular}

Table (1) shows that $(U=18)$, at a significance level of (1) which is statistically insignificant. This confirms the equivalence of the two groups before conducting the experiment of geographical and cosmic concepts test, affirming the first hypothesis: "there are statistically significant differences at the level of $(\alpha \geq 0.05)$ between the means of experimental and control groups' scores for the pre-test of geographical and cosmic concepts".

Cosmic awareness scale was pre-tested on the two groups. Table (2) illustrates the results of Man Whitney test of the differences between the research groups in the pre-test of cosmic awareness scale.

Table (2) Results of Man Whitney test of the differences between the groups in the pre-test of cosmic awareness scale.

\begin{tabular}{cccccc}
\hline Group & Size & $\begin{array}{c}\text { Total of } \\
\text { ranks }\end{array}$ & $\begin{array}{c}\text { Means } \\
\text { of ranks }\end{array}$ & $\begin{array}{c}\text { Man } \\
\text { Whitney } \\
\text { test }\end{array}$ & Significance \\
\hline Experimental & 6 & 37 & 6.17 & & \\
Control & 6 & 41 & 6.83 & & \\
& & & & & \\
\hline
\end{tabular}

Table (2) indicates that $(U=16)$, at a significance level of $(0.744)$ which is statistically insignificant. This affirms the equivalence of the two groups before conducting the experiment of cosmic awareness scale, affirming the second hypothesis: There are statistically significant differences at the level of $(\alpha \geq 0.05)$ between the means of the experimental and control groups' scores in the pre-test of cosmic awareness scale. This assures the third hypothesis that: There are statistically significant differences at the level of $(\alpha \geq 0.05)$ between the means of the experimental and control groups' scores in the pre- 
test of cosmic awareness scale. This affirms the equivalence of the two groups before applying the experiment of the achievement test- cosmic awareness scale.

- Applying teaching using the enrichment program. Teaching of "universe" unit using the enrichment program was conducted of 2 classes weekly. The author was keen on following-up, discussing, answering, following- up the activities and exercises of the female students, in general.

- Post-test of the study's tools: Tools of the study were re-tested on the female students (sample of the study) after studying the enrichment program's topics during the week directly after the experiment.

\section{Testing the Validity of the Second Hypothesis:}

It states that: "there are statistically significant differences at the level of $(\alpha \geq 0.05)$ between the means of experimental and control groups' scores for the post-test of geographical and cosmic concepts".

To test the validity of this hypothesis, arithmetic means, standard deviations and (T) value of the scores of female students of (experimental- control) groups in the post-test of geographical and cosmic concepts scale were estimated. Table (3) illustrates the statistical analysis of this hypothesis:

Table (3) Arithmetic means, standard deviations and (T) value of the scores of female students of (experimental and control) groups in the post-test of geographical and cosmic concepts test

\begin{tabular}{|c|c|c|c|c|c|c|c|}
\hline Group & No. & $\begin{array}{c}\text { Arithmetic } \\
\text { mean }\end{array}$ & $\begin{array}{l}\text { Standard } \\
\text { deviation }\end{array}$ & Difference & $\begin{array}{c}\text { "T" } \\
\text { value }\end{array}$ & $\begin{array}{c}\text { Significance } \\
\text { level }\end{array}$ & Effect size \\
\hline Experimental & 25 & 133.80 & 5.23 & \multirow[t]{2}{*}{72.62} & \multirow[t]{2}{*}{15.67} & significant at & \multirow[b]{2}{*}{85.65} \\
\hline Control & 25 & 61.18 & 22.57 & & & $\begin{array}{c}\text { the level of } \\
0,05\end{array}$ & \\
\hline
\end{tabular}

Table (3) illustrates that $(\mathrm{T})$ value is significant at the level of $(\leq 0.05)$, suggesting statistically significant differences between the means of the experimental and control groups' scores on the post-test of geographical and cosmic concepts test. It also illustrates that the means of the female students of the experimental group's scores rated (133.80), which was greater than that of the control group, rating (61.18). That is, differences were in favor of the experimental group. To measure the effectiveness of the proposed enrichment program to develop geographical and cosmic concepts of high school $2^{\text {nd }}$ grade

female students, Humanities stream, Eta Square $\left(\eta_{\mathbf{2}}\right.$ ) was estimated, rating $(83.65 \%)$. Hence the validity of the second hypothesis was verified.

Therefore, the second question, "what is the effectiveness of a proposed enrichment program in developing geographical and cosmic concepts among the high school 2nd grade female students, Humanities stream?" was answered. 
The fourth hypothesis: It states that: There are statistically significant differences at the level of $(\alpha \geq 0.05)$ between the means of the experimental and control groups' scores for the post-test of cosmic awareness scale.

To test the validity of this hypothesis, arithmetic means, standard deviations and (T) value of the scores of female students of (experimental- control) groups in the post-test of geographical and cosmic concepts scale were estimated. Table (4) illustrates the statistical analysis of this hypothesis:

Table (4) Arithmetic means, standard deviations and (T) value of the scores of female students of (experimental- control) groups in the post-test of geographical and cosmic concepts

\begin{tabular}{lccccccc}
\hline \multicolumn{1}{c}{ Group } & No. & $\begin{array}{c}\text { Arithmetic } \\
\text { mean }\end{array}$ & $\begin{array}{c}\text { Standard } \\
\text { deviation }\end{array}$ & $\begin{array}{c}\text { Differenc } \\
\mathrm{e}\end{array}$ & $\begin{array}{c}\text { "T" } \\
\text { value }\end{array}$ & $\begin{array}{c}\text { Significance } \\
\text { level }\end{array}$ & Effect size \\
\hline Experimental & 25 & 27.26 & 1.60 & 14.4 & 13.97 & & 0.05 \\
Control & 25 & 12.86 & 4.90 & & & & 80.26 \\
\hline
\end{tabular}

Table (4) illustrates that $(\mathrm{T})$ value is significant at the level of $(\leq 0.05)$, suggesting statistically significant differences between the means of the experimental and control groups' scores on the post-test of cosmic awareness scale.

It also illustrates that the means of the female students of the experimental group's scores rated (27.26), which was greater than that of the control group, rating (12.86). That is, differences were in favor of the experimental group.

To measure the effectiveness of the proposed enrichment program to develop cosmic awareness of high school 2nd grade female students, Humanities stream, Eta

Square $\left(\eta_{\mathbf{2}}\right)$ was estimated, rating $(80.26 \%)$. Hence the validity of the fourth hypothesis was verified.

Therefore, the second question, "What is the effectiveness of a proposed enrichment program in developing cosmic awareness among the high school 2nd grade female students, Humanities stream?" was answered.

\section{Discussion}

This agrees with some results that interested in developing space and cosmic concepts. For example, Elattar (2002) aimed to define the wrong concepts of teachers of the earth and space, proposing a treatment program. He affirmed the necessity of interest in cosmic concepts. Mahmoud (2002) aimed to determine the impact of a proposed unit, entitled (earth and atmosphere), according to educational technology on learners' achievement and attitude towards science. She recommended the importance of acquiring cosmic concepts because of their impact on achievement. Jad (2003) was interested in understanding the concepts and issues related to space by the students of Faculties of Education, Science section. It concluded that the sample of the study was unable to study concepts and issues related to space despite their scientific importance. Brunsell \& Marcks (2007) aimed to 
identify learners' understanding of space science scope, offering educational activities that proved its effectiveness in acquiring sound science concepts. Ashmann (2012) aimed to change the frames of reference related to lunar phases among learners by applying a set of activities, resulting in a change of learners' frames of reference.

Results indicated that the proposed enrichment program highly affects developing geographical and cosmic concepts among the high school 2nd grade female students, Humanities stream. The increase of achievement level among female students can be attributed to the following:

- The enrichment program includes knowledge and geographical and cosmic concepts daily required by the female students.

- A different display method; it was far from narration that causes memorizing without understanding. Hence, the cognitive basis of the female students increased.

- The diversity of activities and exercises help undertake studying.

- The diversity of educational and technological aids of programs based on sensory, auditory and visual effects help understand abstract cosmic concepts. This creates enjoyment of learning and understanding the concept and increasing achievement.

- Motivating geographical imaginary thinking and widening understanding consolidated many geographical and cosmic concepts.

The current study measured the effectiveness of the proposed enrichment program on developing cosmic awareness. Results indicated that the proposed enrichment program highly affects developing cosmic awareness among the high school 2 nd grade female students, Humanities stream. The increase of awareness level among female students can be attributed to the following:

- It offers them opportunities to experience and practice the various activities. Thus, they acquired experiences to enable them understand and appropriately apply information.

- The work papers organized according to the enrichment program made it easy for them handle cosmic problems in the unit to be studied.

- Education technology (educational video and PowerPoint) is able to virtualize and imitate nature in displaying cosmic issues and problems, creating concepts and knowledge that form awareness towards these problems.

- The activities of the proposed enrichment program are appropriate to the female students' needs, interests and attitudes, causing increase of motivation to perform activities and not to be stereotypical.

- Cosmic problems were shown because of their effect on life helped improve individual responsibility of the female students. This helped develop cosmic awareness to find direct solutions.

\section{Recommendations}

A set of recommendations are have been made, indicated as follows:

1. Re-conducting the study on different stages and classes to verify the effectiveness of the results.

2. Interest in developing the enrichment programs before and in service to change the view of geography from an achievement course to an enrichment one.

3. Creating other scales to measure cosmic awareness and concepts. 
4. Re-considering current geography courses and enrich them with activities to develop cosmic concepts.

\section{References}

Abdelmowla, O. A. (2010). The effectiveness of social structuralism-based program using mixed learning in teaching social studies on developing geographical concepts, visual thinking and life skills among deaf students of the preparatory stage. (Unpublished Ph.D. thesis. Faculty of Education, Sohag University.

Abuhashem, E. M. (2004). The statistical manual of data analysis using SPSS. Riyadh: Alrushd bookstore.

Ahmad, A. M. (1999). The effectiveness of using some enrichment educational activities in teaching outer space and stars unit in developing creativity and achievement among second preparatory grade pupils. Scientific education journal, 4, 44-59.

Ahmad, M. J. (2012). A thinking maps- based teaching strategy to develop geographical concepts and geographical thinking skills among preparatory stage students. Journal of the educational association for social studies, 42, 117-156.

Alostaz, M. and Matar, M. (2001). Basics of curricula: Concept, structure, organizations, basics and following-up (1st edition). Gaza.

Anderson, T.\& et al.,(1994). A text analysis of two presecondary science activities. Journal of Curriculum Studies, 26 (2), 183.

Ashmann, n. S. (2012). A sun-moon activity to develop student understanding of lunar phases and frames of reference science scope, 35 (6), 32-36.

Awda, A. and Malkawy, F. (1992). Basics of scientific research in education and humanities (2nd ed.). Jordan: Elketany library

Basher, H. (2009). The effect of virtual environment on improving visual conceptualization and space concepts among pre-school children.

Brunsell, E. and Marcks, J. (2007). Teaching for conceptual change in space science scope, 30 (9), 20-23.

Darweesh, D. M. (2013). The effectiveness of visual-spatial approach in developing geographical concepts and spatial ability among intermediate school students. Arab studies in education and psychology, KSA, 40 (3), 220-264.

Eladwan, Z. (2011). The effectiveness of using learning cycle in acquiring geographical concepts among basic 10th grade students in Jordan. The Journal of An-Najah National University for research (Humanities), 25(10), 2583-2608.

Elattar, M. A. (2002). The concepts of earth and space among the teachers of science in the primary stage: An investigative study and a proposed treatment program. Journal of studies in curricula and methods of teaching, 80, 261-292.

Elbarghothy, E. A. et al. (2003). The level of astronomical culture among high school second year students in Al-Quds. Journal of Arab universities association, Jordan, 42, 77-111.

Ellaqany, A. \& Aljamal, A. (1996). Dictionary of educational terms defined in curriculum and methods of teaching. Cairo: Alam Elkotob.

Ellaqany, A. et al. (1999). Methods of teaching social studies (1st ed.). Amman: Dar Al Thaqafa for publishing \& distributing.

Elobedy, H. A. (2006). The impact of using learning differences in acquiring and memorizing the geographical concepts among the middle first-grade female students in Geography. (Unpublished MA. thesis). College of Education: University of Baghdad. 
Jad, E. A. (2003). Understanding the concepts and issues related to space by the students of Faculties of Education, Science section. Journal of Banha Faculty of Education, $35,131-160$.

Mahmoud, A. M. (2002). Preparing meteorology and atmosphere for preparatory first year students according to educational technology and its impact on achievement and attitude towards science. Journal of studies in curricula and methods of teaching, $80,15-40$.

Muhammad, N. (2013). The effectiveness of an enrichment program on developing some scientific concepts of the talented kindergarten child according to needs. Journal of childhood and education, Faculty of Kindergarten, Alexandria University, 5(14), 345-441.

Qanou, M. J. (2013). Enriching the content of geography with Qur'anic verses and its impact on developing geographic concepts and attitudes among basic education fifth grade female students in Gaza. (Unpublished master thesis). College of Education of Education, Islamic University.

Shehata, H. and Elnajar, Z. (2003). Dictionary of educational and psychological terms. Cairo: Al Dar Al Masriah Al Lubnaniah.

Soliman, A. Y. (2010). Multiple-intelligences (A window on talent, excellence and creation). Mansoura: Elasrya Publishing House.

Tammam, S. A. (2012). The effectiveness of a proposed enrichment program in sociology to develop the awareness of social problems and citizenship culture among high school students. Journal of Arab studies in education and psychology, KSA, 30 (1), 111-170.

Zaetoun, A. (2004). Methods of teaching science. Jordan: Dar El Shorouk.

Zaetoun, K. (2005). Teaching: Its forms and skills. Alexandria: The scientific office for publication and distribution. 